\title{
Lack of reinstatement of an extinguished taste aversion
}

\author{
MARK E. BOUTON \\ University of Vermont, Burlington, Vermont
}

\begin{abstract}
Three experiments with rat subjects were designed to investigate the possibility that an extinguished saccharin aversion might be reinstated if the animals are made ill with lithium chloride (in the absence of saccharin) following extinction. Although reinstatement can be obtained when the unconditioned stimulus is presented following the extinction of other kinds of conditioned behaviors, the present experiments provided no evidence that an extinguished taste aversion can be reinstated. No reinstatement was observed, even when the aversion had been only partially extinguished and when multiple injections of lithium chloride were administered in an attempt to reinstate the aversion.
\end{abstract}

An extinguished conditioned stimulus (CS) may regain some of its ability to evoke conditioned behavior if the unconditioned stimulus (US) is presented by itself after extinction. The renewed response to the CS resulting from presentation of the US following extinction is known as "reinstatement" (e.g., Rescorla \& Heth, 1975). Reinstatement has been widely obtained when the US is presented after the extinction of conditioned suppression (e.g., Bouton, 1980; Bouton \& Bolles, 1979; Hoffman, 1965; Quinsey \& Ayres, 1969; Rescorla \& Cunningham, 1977, 1978; Rescorla \& Heth, 1975). It has also been obtained following the extinction of salivary conditioning (Pavlov, 1927). The experiments reported in the present article were designed to determine whether an extinguished illnessinduced taste aversion can also be reinstated if the US is presented following extinction. To my knowledge, there are presently no reports of this effect in the taste aversion literature.

There are currently two accounts of reinstatement as it occurs in the conditioned suppression paradigm. One account is based on Rescorla's event-memory model of Pavlovian conditioning (e.g., Rescorla, 1973, 1974). According to the event-memory model, conditioning involves not only the formation of an association between the CS and US, but also the construction of memories about those events themselves. The model suggests that the strength of the response evoked by the CS is a function of (1) the strength of the CS-US association and (2) the strength of the animal's memory of the US. According to the model, extinction of responding ordinarily occurs because the memory of the US is weakened when the CS is

This research was supported by an institutional grant from the University of Vermont. I thank Jennifer Hall, Alison Hill, and Tracy Blodgett for their help in conducting the experiments. Send correspondence to Mark E. Bouton, Department of Psychology, University of Vermont, Burlington, Vermont 05405. presented without the US during extinction (e.g., Rescorla \& Heth, 1975). When the US is then presented following extinction, it restrengthens the memory of the US, and thus reinstates conditioned responding.

Bouton and Bolles (1979) have suggested an alternative account of reinstatement. They noted that contextual stimuli, stimuli arising from the experimental background, are likely to be conditioned when the US is presented following extinction. Reinstatement will then occur if the extinguished CS is tested for reinstatement in the presence of the newly conditioned contextual cues, because undetected associative strength that is known to remain to an extinguished CS may summate with the excitatory strength of the context. Consistent with this account, Bouton and Bolles (1979) found reinstatement of conditioned suppression when presentation of the US and reinstatement testing occurred in the same context. But when US presentation and testing were conducted in different contexts, reinstatement was not observed. Such evidence suggests that reinstatement may depend upon the conditioning of contextual stimuli.

Recent evidence suggests that the conditioning of contextual stimuli may also be involved in taste aversion learning (e.g., Archer \& Sjödén, 1981; Archer, Sjödén, Nilsson, \& Carter, 1979, 1980; Batson \& Best, 1979; Krane, 1980; Willner, 1978). We therefore began our investigation of the reinstatement of taste aversions by attempting to determine whether reinstatement would occur only if the US were presented in the context in which the aversion was subsequently tested for reinstatement.

\section{EXPERIMENT 1}

The design of the first experiment was patterned after a design used by Bouton and Bolles (1979, Ex- 
periment 1). Its most salient features are illustrated in Table 1. Three groups of rats initially received exposure to saccharin and lithium chloride $(\mathrm{LiCl})$ in the home room, here referred to as the "conditioning context." For two of the groups (Groups TC and $\mathrm{CC}$ ), saccharin and $\mathrm{LiCl}$ were paired. For the third group (Group BC, for "backward"' conditioning), saccharin and $\mathrm{LiCl}$ were presented in a manner that was not expected to produce conditioning. Following the conditioning treatment, the animals were given several trials in which the consumption of saccharin was not followed by $\mathrm{LiCl}$. These extinction trials were conducted in a different room in the laboratory, the "test context." When the taste aversion had been extinguished, each of the groups was given a single injection of $\mathrm{LiCl}$. The groups differed with respect to the context in which this reinstatement injection was received. One of the groups that had originally received a saccharin- $\mathrm{LiCl}$ pairing, Group TC (for reinstatement in the test context), received its injection in the test context. The other group that had received an initial saccharin- $\mathrm{LiCl}$ pairing, Group $\mathrm{CC}$ (for reinstatement in the conditioning context), received the same injection back in the conditioning context. Group BC, the conditioning control group, received its $\mathrm{LiCl}$ injection in the test context. Seventytwo hours after the reinstatement injections, the rats' aversion to saccharin was tested again in the test context. Reinstatement would be manifest if Group TC or CC showed a renewal of their extinguished saccharin aversion during testing. Based on Bouton and Bolles's work with the reinstatement of conditioned suppression, we expected that reinstatement was most likely to occur in Group TC, the conditioned group that had received the reinstatement injection in the context in which testing occurred.

\section{Method}

Subjects. The subjects were 18 female Long-Evans rats, approximately 150 days of age at the start of the experiment. They were individually housed in $36 \times 17.2 \times 17.2 \mathrm{~cm}$ stainless steel and wire-mesh cages in a room maintained on a 12:12-h day/night cycle. The experiment was conducted during the day.

Apparatus. Two contexts were provided by two rooms in the laboratory. The "conditioning context" was provided by the rats' home colony room. It was illuminated by fluorescent light fixtures mounted in the ceiling. This room was relatively quiet ( $44 \mathrm{~dB}$ on the A scale of a General Radio 1551-C sound-level meter) during all phases of the experiment. Fluids were delivered to the animals in their home cages. The "test context" was a different room located $4 \mathrm{~m}$ down the hall from the conditioning-context room. It was dark except for the light provided by a single $100-\mathrm{W}$ red incandescent bulb. A radio played constantly and provided a background noise level of approximately $70 \mathrm{~dB}$ at the location of the animals. Once individually transported by hand to the test context, each rat was placed in a cage that was identical to the home cage.

Experimental solutions were presented to the rats via modified 30-ml polyethylene syringes with $6.3-\mathrm{cm}$ stainless steel spouts mounted on the ends of them. When these drinking tubes were attached to the front of the cages in either context, the stainless steel spout extended $3.5 \mathrm{~cm}$ into the cage, $8 \mathrm{~cm}$ above the floor. Consumption was measured to the nearest milliliter.

Procedure. Initially, the animals were trained to drink distilled water from the tubes within $20 \mathrm{~min}$ at the same time each day. Water was unavailable at any other time during the experiment. At the designated time each day, food was removed from the hopper mounted on the front of the cage, the animal was weighed, and the fluid was then presented for $20 \mathrm{~min}$. Food was returned within $10 \mathrm{~min}$ after the drinking period. Drink-training consisted of 8 days of this treatment in the home room (the conditioning context). On the next 2 days, each rat was transported to the test context after being weighed and then given distilled water there. Six of the rats were assigned to the conditioning control group (Group BC) so as to match their consumption with that of the remaining rats on these final days of drink-training.

A single conditioning trial was administered in the conditioning context on the day following the completion of drink-training. Twelve of the animals (subsequently assigned to Groups TC and CC) were given a novel .1\% (weight/volume) saccharin solution at the usual drinking time. The remaining six rats (Group BC, for "backward" conditioning) received distilled water on this day. Every animal was given an intraperitoneal injection of a .6-M $\mathrm{LiCl}$ solution at $5 \mathrm{ml} / \mathrm{kg}$ body weight within $10 \mathrm{~min}$ after drinking. Food was returned to the cage $1 \mathrm{~h}$ after the injection. Two recovery days conducted in the conditioning context followed the conditioning trial. The 12 rats that had received the saccharin$\mathrm{LiCl}$ pairing (Groups $\mathrm{TC}$ and $\mathrm{CC}$ ) received distilled water on these

Table 1

Treatment Conditions in the Three Experiments

\begin{tabular}{|c|c|c|c|c|}
\hline \multirow[b]{2}{*}{ Group } & \multirow[b]{2}{*}{ Conditioning (in CC) } & \multicolumn{2}{|c|}{ Phase } & \multirow[b]{2}{*}{ Test (in TC) } \\
\hline & & Extinction (in TC) & Reinstatement & \\
\hline \multicolumn{5}{|c|}{ Experiment 1} \\
\hline TC & Sacc-LiCl & Sacc & $\mathrm{LiCl}$ in $\mathrm{TC}$ & Sacc \\
\hline $\mathrm{CC}$ & Sacc-LiCl & Sacc & $\mathrm{LiCl}$ in $\mathrm{CC}$ & Sacc \\
\hline $\mathrm{BC}$ & LiCl; Sacc & Sacc & $\mathrm{LiCl}$ in $\mathrm{TC}$ & Sacc \\
\hline \multicolumn{5}{|c|}{ Experiment 2} \\
\hline $\mathrm{R}$ & Sacc-LiCl & Sace & $\mathrm{LiCl}$ in $\mathrm{TC}$ & Sacc vs. Water \\
\hline $\mathrm{N}$ & Sacc-LiCl & Sacc & & Sacc vs. Water \\
\hline \multicolumn{5}{|c|}{ Experiment 3} \\
\hline R-3 & Sacc-LiCl & Sacc & $3 \mathrm{LiCl}$ in $\mathrm{TC}$ & Sacc vs. Water \\
\hline R-1 & Sacc-LiCl & Sacc & $1 \mathrm{LiCl}$ in $\mathrm{TC}$ & Sacc vs. Water \\
\hline $\mathrm{N}$ & Sacc-LiCl & Sacc & & Sace vs. Water \\
\hline $\mathrm{BC}$ & $\mathrm{LiCl} ; \mathrm{Sacc}$ & Sacc & $3 \mathrm{LiCl}$ in $\mathrm{TC}$ & Sacc vs. Water \\
\hline
\end{tabular}

Note-Sacc $=$ saccharin $; C C=$ conditioning context $; C=$ test context. 
days. Group BC received the saccharin solution on the first recovery day and distilled water on the next. Group BC thus received exposure to both saccharin and $\mathrm{LiCl}$, but in a manner that was not expected to produce conditioning.

The extinction phase of the experiment began on the day following the 2 nd recovery day. During this phase, each rat was allowed to drink saccharin in the test context on seven trials without $\mathrm{LiCl}$. For each extinction trial, the animals were weighed and then transported to a cage in the test context. Saccharin was presented to all of the rats simultaneously for $20 \mathrm{~min}$. No other fluid was available on these days. Extinction trials were conducted every other day; the rats consumed distilled water in the conditioning context on the intervening days. The 12 conditioned animals were assigned to Groups TC and CC so as to match their saccharin consumption during the first two extinction trials.

On the day following the last extinction trial, every rat was injected with $.6-\mathrm{M} \mathrm{LiCl}$ at $5 \mathrm{ml} / \mathrm{kg}$ body weight. Following the design used by Bouton and Bolles (1979, Experiment 1), the groups differed with respect to the context in which they received the reinstatement injection. One of the groups that had received a saccharin-LiCl pairing, Group TC (reinstatement in the test context), received the injection in the test context. The conditioning control group, Group BC, also received the injection in the test context. Animals in the remaining conditioned group, Group CC (reinstatement in the conditioning context), received the injection in the conditioning context. Each group was injected within $10 \mathrm{~min}$ after consuming distilled water in the appropriate context. The injections produced marked immobility in the animals, indicating that the $\mathrm{LiCl}$ had made them ill. The rats that were injected in the test context (Groups TC and BC) remained in that context for 60 min following the injection before they were returned to their home cages. Rats in Group $\mathrm{CC}$ were left undisturbed, except that food was returned to the cage $60 \mathrm{~min}$ after the injection. On the 2 recovery days that followed the reinstatement day, each group was given distilled water in the conditioning context.

Beginning on the day following the second reinstatement recovery day, reinstatement of the rats' aversion to saccharin was assessed by means of a series of one-bottle tests conducted in the test context. On each test day, the rats were transported to the test context and allowed to drink saccharin for 20 min there. No other fluid was available. There were three such test trials given every other day. The rats consumed distilled water in the home room (the conditioning context) on the intervening days.

\section{Results and Discussion}

Saccharin consumption during each extinction and reinstatement test trial is shown in Figure 1. On the initial extinction trial, the groups that had received a saccharin-LiCl pairing (Groups TC and CC) consumed far less saccharin than did the conditioning control group (Group BC). This impression was confirmed by an analysis of variance $[F(2,15)=46.83$, $\mathrm{p}<.01$ ]. Pairwise comparisons using Duncan's multiple range tests revealed that Groups TC and CC consumed less saccharin than Group BC (ps $<.01$ ) and that Group TC and CC did not differ from one another $(p>.10)$. The marked aversion shown by Groups TC and CC extinguished over trials during extinction, so that there were no reliable differences among the groups on the final extinction trial $[F(2,15)$ $<1]$. Thus, extinction appeared to be complete at the end of this phase.

As the figure suggests, there was little indication of any effect of the reinstatement injection on saccharin consumption in any of the groups. Each rein-

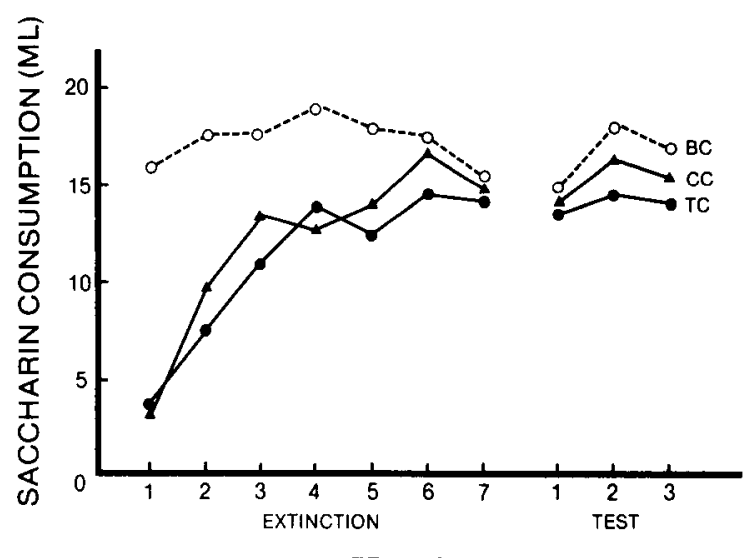

TRIALS

Figure 1. Mean saccharin consumption during each extinction and reinstatement test trial in Experiment 1.

statement test trial was analyzed individually. On the first test trial, on which prior reinstatement research suggests we should have found the strongest evidence of reinstatement, the overall difference among the groups fell far short of statistical reliability $[F(2,15)$ $<1]$. None of the groups exhibited a reliable change in saccharin consumption on the first test relative to the final extinction trial $[t s(5) \leqslant .53$, ps $>.10]$. Analyses of variance on the remaining two test trials further failed to reveal reliable differences among the groups $[F s(2,15) \leqslant 2.68$, ps $>.10]$.

The results of this experiment provide no evidence for the notion that an extinguished taste aversion can be reinstated. Under the present circumstances, we failed to find the relatively robust reinstatement effect that Bouton and Bolles (1979) found in a group analogous to Group TC in their investigation of the reinstatement of extinguished fear. Given the difficulty in accepting a null hypothesis, however, it was necessary to assess the generality of these findings after attempting to maximize the possibility of detecting reinstatement if such an effect can indeed occur. The next two experiments were designed with this goal in mind.

\section{EXPERIMENT 2}

The second study was designed to assess a possible reinstatement effect by comparing a "reinstated" group with a spontaneous recovery control group that had had no experience with the US following extinction. The second study incorporated several features that were expected to increase the experiment's power to detect a reinstatement effect. First, the number of animals involved in each group was increased to eight. Second, two-bottle preference tests, which provide a more sensitive measure of taste aversions, were used during reinstatement testing. Third, the animals were given a smaller number of extinction trials before a reinstatement presentation 
of the US was made. Since reinstatement in other conditioning paradigms appears to depend upon some undetected associative strength remaining to the CS following extinction (e.g., Bouton \& Bolles, 1979 ), the use of a small number of extinction trials was expected to enhance the possibility of associative strength remaining to saccharin, therefore allowing for reinstatement. Fourth, Wistar rats were used, because reliable reinstatement of fear had previously been obtained in this strain (Bouton, 1980; Bouton \& Bolles, 1979). Finally, we continued to focus on reinstatement in a context that differed from the home room because this procedure allowed us to limit the rats' exposure to the context in which the reinstatement US was received. Such exposure may tend to injure reinstatement (Bouton \& Bolles, 1979). The design of Experiment 2 is illustrated in Table 1.

\section{Method}

Subjects. The subjects were 16 male Wistar rats approximately 120 days old at the start of the experiment. They were maintained under conditions that were identical to those of the preceding experiment.

Apparatus. The same drinking tubes, saccharin solution, and $\mathrm{LiCl}$ injections were used. The conditioning context, that is, the home room, was also the same. However, a new room, $18 \mathrm{~m}$ down the hall from the home room, served as the present test context. The cages, illumination, and noise level in this room were the same as in the room used as the test context in the preceding experiment.

Procedure. The rats were trained to drink distilled water for 20 min a day in the home room for 8 days, following the procedure used in Experiment 1 . On the 9th day, they were individually weighed and then transported to the test context, in which they were allowed to drink distilled water for $20 \mathrm{~min}$. On the following day, each rat was given the saccharin solution in the conditioning context followed immediately by an injection of $\mathrm{LiCl}$. Two recovery days in which the animals drank distilled water in the conditioning context followed the conditioning day. The extinction phase began on the day following the 2 nd recovery day. On odd-numbered days of this phase, the rats were allowed to drink saccharin in the test context for $20 \mathrm{~min}$. On even-numbered days, they were given distilled water in the conditioning context. The rats were given only the tube containing saccharin during the first four extinction trials. The fifth extinction trial, however, was a two-bottle test in which the animals were allowed to drink from either a tube containing saccharin or a tube containing distilled water. The animals first lapped at one tube, it was withdrawn, and then the second tube was similarly introduced and withdrawn. Then both tubes were returned to their respective positions and left there for 20 min. A random half of the animals received saccharin on the left; the other half received saccharin on the right. This two-bottle test constituted a "pretest" with which the subsequently reinstated aversion could be compared.

The rats were divided into two groups so as to match their preference for saccharin during the pretest. The groups differed with respect to their treatment on the day that followed the pretest. On that day, rats from both groups were returned to the test context, in which they drank distilled water for 20 min. Rats in Group R (reinstatement) were injected with $\mathrm{LiCl}$ immediately after drinking. Observation of the animals indicated that the injection made them ill. Rats in Group N (no reinstatement) were not injected. All of the animals remained in the test context for $30 \mathrm{~min}$ following the injections given Group $R$, and then were returned to the home room.

On the next 2 days, the rats were given distilled water in the home room. On the $3 \mathrm{rd}$ day, the animals were returned to the test context for reinstatement testing. At that time, they were given a two-bottle test (saccharin vs. distilled water) following the procedure used during the pretest. The positions of the saccharin and water tubes were reversed from those used during the pretest. As on every other day, the rats were allowed to drink for $20 \mathrm{~min}$. Reinstatement would be manifest if Group $\mathbf{R}$ demonstrated a decreased preference for saccharin on the reinstatement test trial.

\section{Results and Discussion}

The conditioning and extinction treatments produced equivalent effects on saccharin consumption in the two groups. On the first extinction trial, Groups $\mathbf{R}$ and $\mathrm{N}$ consumed an average of 2.0 and $3.1 \mathrm{ml}$ of saccharin, respectively. The difference between the groups was not reliable $[F(1,14)=1.39, p>.10]$. Saccharin consumption increased steadily in both groups such that by the fourth and final one-bottle extinction trial, Groups $\mathbf{R}$ and $\mathbf{N}$ respectively consumed an average of 14.7 and $17.1 \mathrm{ml}$ of saccharin. Saccharin consumption had increased reliably in each of the groups $[\operatorname{ts}(7) \geqslant 11.56$, ps $<.01]$, but to comparable levels. The difference between the groups on the fourth one-bottle test was not reliable $[F(1,14)$ $=1.76, p>.10]$.

During the two-bottle tests that preceded and followed the reinstatement treatment, Group N's mean saccharin preference (percentage of the total fluid consumed that was saccharin) was $58 \%$ in the pretest and $70 \%$ in the posttest. The corresponding scores for Group R were $57 \%$ and $74 \%$. The groups did not differ in their preference for saccharin in either the pretest or the posttest $[\mathrm{Fs}(1,14)<1]$. Saccharin preference tended to increase rather than decrease between the pre- and posttests in both groups, although this tendency was not reliable in either group $[\operatorname{ts}(7)$ $\leqslant 1.45$, ps $>.10$ ]. It is apparent from the preference data that no reinstatement of the extinguished saccharin aversion was observed in this experiment.

The overall fluid consumption (saccharin plus distilled water) during two-bottle testing was also examined. Unlike the preference scores, which provide a direct measure of the saccharin aversion, overall fluid consumption provides a measure of the nonspecific effects of reinstatement on general fluid intake. Groups $\mathbf{R}$ and $\mathbf{N}$ did not differ in overall fluid consumption during the pretest $[F(1,14)<1]$, when these groups drank a total of 22.0 and $22.9 \mathrm{ml}$, respectively. However, the two groups did differ in the overall amount consumed during the posttest. At that time, Group R drank $18.6 \mathrm{ml}$ and Group $\mathrm{N}$ drank $22.9 \mathrm{ml}$. The difference between the groups was reliable $[F(1,14)=5.25, p<.05]$. It is important to note that the groups did not differ in their consumption of water in the home room on the preceding recovery day $[F(1,14)=2.96, p>.10]$. The depressed consumption in Group $R$ on the test day cannot be interpreted as a reinstated aversion to saccharin, because there was no decrease in Group R's 
preference for saccharin on that day. Instead, it appears to reflect a more general tendency to decrease fluid consumption in the context in which the reinstatement injection was received. Krane (1980) and Willner (1978) have reported a similar decrease in general fluid consumption in a context in which rats received injections of $\mathrm{LiCl}$. Such an effect in the present experiment appears to have occurred independently of any reinstatement of the saccharin aversion, because Group R's preference for saccharin did not decrease as a result of the reinstatement injection.

Like Experiment 1, the second experiment failed to produce evidence that an extinguished saccharin aversion can be reinstated. There was no evidence of reinstatement even though the present study included several features that were expected to enhance our ability to detect reinstatement, such as two-bottle preference tests, fewer extinction trials, and an increased number of subjects involved in each group. Under the improved conditions of Experiment 2, there was still no support for the notion that an extinguished taste aversion can be reinstated by postextinction exposure to the US.

\section{EXPERIMENT 3}

In the third study, we attempted to enhance even further our ability to detect reinstatement. All of the desirable features of Experiment 2, such as the twobottle tests, and a small number extinction trials, were retained. In addition, it was plausible that an increased number of reinstatement exposures to $\mathrm{LiCl}$ would increase the strength of any reinstatement effect. In the present experiment, one group of animals received one reinstatement exposure to $\mathrm{LiCl}$, as in the preceding experiments, but another group received three such exposures to $\mathrm{LiCl}$ following extinction. Spontaneous recovery and conditioning control groups were also included. The design of Experiment 3 is illustrated in Table 1.

\section{Method}

Subjects. The subjects were 32 male Wistar rats, 90 days old at the start of the experiment. They were housed under conditions identical to those of the preceding experiments.

Apparatus. The rooms were the same as those used in Experiment 2. The drinking tubes, saccharin solution, and $\mathrm{LiCl}$ injections were the same as in both of the preceding experiments.

Procedure. The procedure was the same as in Experiment 2, except as noted. The rats were initially trained to drink distilled water in the conditioning context over 7 consecutive days; on the 8th day, they drank distilled water in the test context. On the following day, 24 of the rats drank the saccharin solution followed immediately by an injection of $\mathrm{LiCl}$. This conditioning trial was conducted in the conditioning context. The remaining 8 animals (Group BC, for "backward" conditioning) drank water on this day, but received the same $\mathrm{LiCl}$ injection as did the other animals. Two recovery days conducted in the conditioning context followed this day. The 24 rats that had received the saccharin- $\mathrm{LiCl}$ pairing drank distilled water on both recovery days; the rats in Group BC drank saccharin on the $1 \mathrm{st}$ and distilled water on the $2 \mathrm{nd}$.
An extinction procedure identical to the one used in Experiment 2 began on the day following the 2nd recovery day. Every rat was allowed to drink only saccharin in the test context every other day. On intervening days, the animals drank distilled water in the home room. The fifth extinction trial consisted of a twobottle pretest (saccharin vs. distilled water) conducted as in the two-bottle testing procedure used in Experiment 2.

The reinstatement phase began on the day following the pretest. This phase lasted 9 days, with reinstatement injections of $\mathrm{LiCl}$ given on Days 1, 4, and 7. Groups R-3 (reinstatement, three injections) and $\mathrm{BC}$ received $\mathrm{LiCl}$ injections on Days 1,4 , and 7. Group R-1 (reinstatement, one injection) received an injection only on Day 7. Observation of the animals indicated that each reinstatement injection made them ill. Group $\mathbf{N}$ (no reinstatement) was never injected during this phase. In this experiment, the reinstatement injections were given $3 \mathrm{~h}$ before the rats drank distilled water at their accustomed drinking time. When reinstatement injections were to be administered, all of the groups were transported to the test context, but were given no solutions to drink. Animals in the appropriate groups immediately received $\mathrm{LiCl}$ injections, and $20 \mathrm{~min}$ later all of the rats were returned to the home room. Distilled water was delivered $3 \mathrm{~h}$ later at the accustomed time in the conditioning context, as on every other day of this phase. At the end of the phase, Groups R-3 and BC had received three reinstatement injections of $\mathrm{LiCl}$, Group R-1 had received one, and Group $\mathrm{N}$ had received none.

Reinstatement testing began on the day following the 2 recovery days that followed the final $\mathrm{LiCl}$ injections on Day 7. There were two two-bottle test trials (saccharin vs. distilled water) conducted in the test context. A day during which the rats consumed distilled water in the conditioning context was interpolated between these two tests.

\section{Results and Discussion}

The saccharin consumption of the various groups during each of the one-bottle extinction trials is shown in Figure 2. As the figure suggests, the groups that had received a saccharin-LiCl pairing (Groups $\mathrm{N}$,

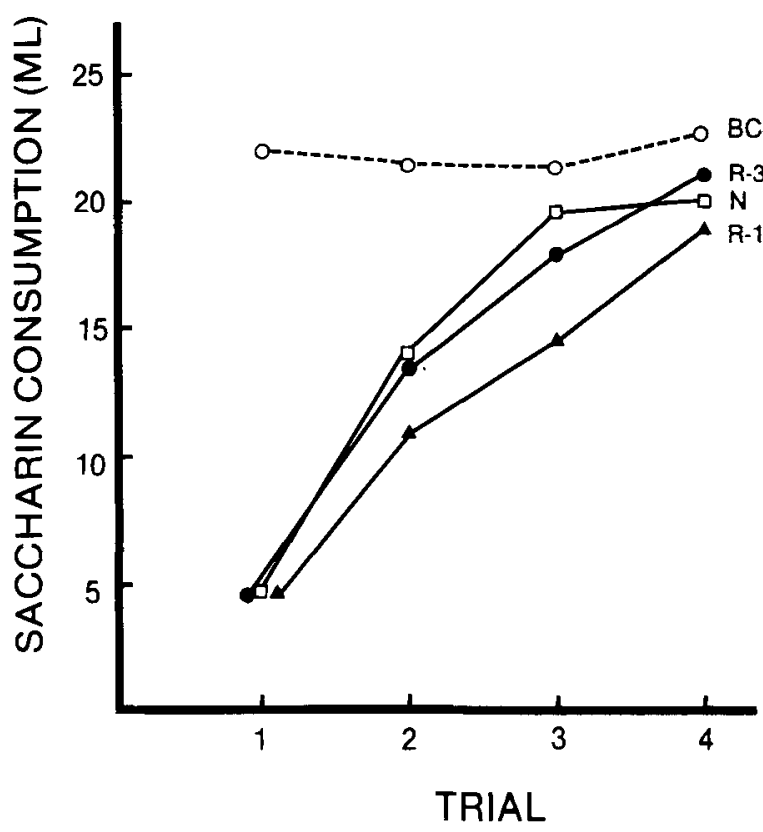

Figure 2. Mean saccharin consumption during each one-bottle extinction trial in Experiment 3. 
R-1, and R-3) initially consumed far less saccharin than did the conditioning control group (Group BC). On the first trial, the difference among the groups was highly reliable $[F(3,28)=56.79, p<.01]$. Pairwise comparisons using Duncan's multiple range tests revealed that Groups N, R-1, and R-3 each consumed reliably less saccharin than Group BC (ps $<$ .01 ), but did not differ from one another ( $\mathrm{ps}>.10$ ). By the fourth one-bottle extinction trial, the aversion in these groups had extinguished such that the difference among the groups was not reliable $[F(3,28)=$ $2.74, \mathrm{p}>.05]$.

Saccharin preference during the two-bottle tests that preceded and followed the reinstatement injections is shown in Figure 3. Interestingly, although the groups had not differed reliably during the final one-bottle extinction trial, they did differ reliably in their preference for saccharin during the two-bottle pretest $[F(3,28)=4.00, p<.025]$. Pairwise comparisons using Duncan's multiple range tests revealed that Groups R-1 and R-3 showed less preference for saccharin than did Group BC (ps $<.05$ ). This difference suggests that there was still a modest aversion to saccharin in Groups R-1 and R-3 at the end of the extinction phase. The difference between Groups $\mathrm{N}$ and $\mathrm{BC}$ fell short of the conventional criterion for statistical significance $(.05<p<.10)$, but the differences between Groups N, R-1, and R-3 were not reliable (ps $>.10)$. When compared with the results of the final one-bottle extinction trial, the results of

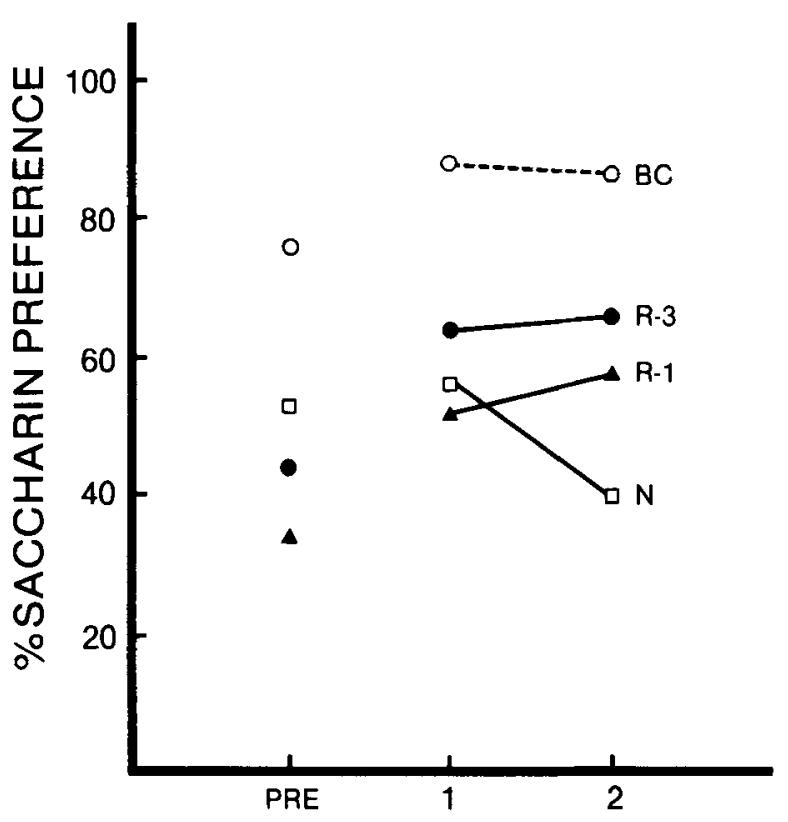

TRIAL

Figure 3. Mean saccharin preference for each group during twobottle testing in Experiment 3 . The two-bottle test that preceded the reinstatement phase (pre) is shown on the left; Trials 1 and 2 are reinstatement test trials. the pretest tend to confirm that the two-bottle test may be a more powerful measure of a modest taste aversion. The pretest results also suggest that the relatively small number of extinction trials used here was not sufficient to eliminate completely the saccharin aversion that had been conditioned in Groups R-1 and R-3. Since reinstatement research with other conditioning paradigms suggests that reinstatement depends partly on some associative strength remaining to the CS following extinction (e.g., Bouton \& Bolles, 1979), the results of the pretest suggest that we were in a strong position to observe reinstatement in Groups R-1 and R-3.

However, consistent with the results of Experiments 1 and 2, there was no evidence that exposure to $\mathrm{LiCl}$ following extinction increased the aversion to saccharin in either Group R-1 or Group R-3. The preference data from the two test trials were analyzed separately. On the first test trial, on which reinstatement was expected to be strongest, the groups did not differ reliably $[F(3,28)=2.10, p>.10]$. However, on the second test trial, a reliable difference among the groups did emerge $[F(3,28)=2.99, p<.05]$. Pairwise comparisons with Duncan's multiple range tests revealed that the only reliable difference was between Groups $N$ and BC $(p<.05)$. Thus, the group that had received no reinstatement injection following extinction showed less preference for saccharin than did the conditioning control. Groups R-1 and R-3 did not differ from each other, from Group $N$, or from Group BC (all ps $>.10$ ). The data suggest that $\mathrm{LiCl}$ injections given to Groups R-1 and R-3 following extinction did not reinstate the partially extinguished saccharin aversion in these groups.

Since the groups entered the reinstatement phase of the experiment with reliably different preferences for saccharin, it was desirable to compare the animals' preference for saccharin during reinstatement testing after correcting for the different preferences evident during the pretest. Difference scores were therefore computed by subtracting each animal's preference score during the pretest from the preference score obtained during each of the two reinstatement tests. The mean difference scores for each group on each reinstatement test trial are given in Table 2. A difference score of 0 indicates no change in saccharin preference from the pretest, while positive and negative difference scores indicate increased and decreased preference for saccharin, respectively. A reinstated aversion to saccharin would be indicated by a negative difference score. This transformation of the data further failed to reveal a reinstated aversion in Groups R-1 and R-3. If anything, the reinstatement injections appeared to increase, rather than decrease, the saccharin preference of these groups relative to the noninjected control group (Group $N$ ). The difference scores from each trial were analyzed separately. On the first trial, there was no reliable 
Table 2

Mean Difference in Saccharin Preference Between Each Reinstatement Test Trial and the Pretest (Test - Pretest) of Experiment 3

\begin{tabular}{ccc}
\hline Group & Test Trial 1 & Test Trial 2 \\
\hline BC & +.12 & +.10 \\
$\mathrm{~N}$ & +.03 & -.12 \\
$\mathrm{R}-1$ & +.19 & +.23 \\
$\mathrm{R}-3$ & +.19 & +.21 \\
\hline
\end{tabular}

difference among the groups $[F(3,28)<1]$. However, the groups did differ reliably on the second test trial $[F(3,28)=6.30, p<.01]$. The configuration of Groups R-1, R-3, and N on this trial was exactly the opposite of what would be expected if the taste aversion had been reinstated in Groups R-1 and R-3. This impression was confirmed by Duncan's multiple range tests. The difference scores of Groups R-1 and R-3 were reliably larger than those of Group $N$ (ps $<$ .01 ). Thus, relative to the pretest, the animals in Groups R-1 and R-3 came to prefer saccharin more than did the animals in Group N. Group N's difference scores were reliably smaller than Group BC's $(p<.05)$. And, in contrast, Groups R-1 and R-3 did not differ from one another $(p>.10)$ or from Group BC (ps > .10).

The present findings cannot in any way be taken to confirm the hypothesis that a partially extinguished taste aversion can be reinstated. If anything, the reinstatement injections given Groups R-1 and R-3 appeared to increase the rats' preference for saccharin relative to Group N. It may be appropriate to note that the reinstatement procedure can in one sense be considered an inhibitory operation, potentially capable of producing an increase in saccharin preference (cf. Best, 1975), because it establishes a negative correlation between the CS and US (cf. Rescorla, 1969). However, it is apparent that the excitatory effect of presenting the US after extinction that is more commonly found in other conditioning paradigms was not obtained here.

The overall consumption of saccharin and distilled water during the two-bottle tests was also analyzed. The groups' overall consumption did not differ reliably during the pretest or either of the reinstatement test trials $[\mathrm{Fs}(3,28) \leqslant 2.20$, ps $>.10]$. During the pretest and first and second reinstatement tests, respectively, Group BC drank 21.1, 21.8, and $22.0 \mathrm{ml}$, Group N drank 18.6, 18.2, and $19.9 \mathrm{ml}$, Group R-1 drank 21.5, 17.2, and $19.1 \mathrm{ml}$, and Group R-3 drank $20.9,21.1$, and $21.5 \mathrm{ml}$.

Like the results of Experiments 1 and 2, the results of Experiment 3 provided no support for the hypothesis that an extinguished taste aversion can be reinstated. This conclusion is particularly significant in the case of Experiment 3, because here there was no evidence of reinstatement in a group that received multiple injections of $\mathrm{LiCl}$ following extinction. It would be difficult to argue that the three injections given Group R-3 were not a potent enough treatment to produce reinstatement. And there was evidence to suggest that reinstatement injections following extinction increased, rather than decreased, the animals' preference for saccharin. We have never observed the reinstatement of an extinguished taste aversion.

\section{GENERAL DISCUSSION}

Under the various conditions studied in the present experiments, there was no evidence that exposure to illness after extinction can reinstate a rat's aversion to saccharin. There was no evidence of reinstatement in two strains of rats, including a strain in which reinstatement of fear has been demonstrated. And we failed to find reinstatement even though several features of the present experiments should have enhanced our ability to produce and detect the effect. For example, there was no evidence of reinstatement when we tested with two-bottle preference tests after giving the animals a number of extinction trials that only partially extinguished the aversion (Experiments 2 and 3). Multiple injections of $\mathrm{LiCl}$ were no more effective than single injections in reinstating the aversion (Experiment 3). And, in addition, since exposure to contextual stimuli associated with the reinstatement US may tend to injure reinstatement (Bouton $\&$ Bolles, 1979), the fact that we attempted to limit the rats' exposure to the context in which they had received the reinstatement injections could have further increased the chance of observing reinstatement. In spite of such factors, however, no reinstatement of the saccharin aversion was ever observed. Indeed, there was some evidence to suggest that illness following extinction might increase rather then decrease the rat's preference for saccharin (Experiment 3). The present results suggest that if there are excitatory effects of postextinction exposure to illness on an extinguished taste aversion, they are not likely to contribute significantly to behavior in the rat.

These results were not anticipated by the eventmemory model (e.g., Rescorla \& Heth, 1975) or by the context-conditioning account of the reinstatement effect that has been observed in other paradigms (Bouton \& Bolles, 1979). According to the event-memory model, presentation of the US following extinction should be sufficient to reinstate the memory of the US that was weakened during extinction. The present data suggest that the presentation of a US may not always be sufficient to reinstate an extinguished response. The event-memory model does predict that presentation of the US may not reinstate an extinguished response under conditions in which the CS-US association, rather than just the memory of the US, has been weakened substantially during extinction (e.g., Rescorla \& Cunningham, 
1978). Thus, if the CS-US association had been lost during extinction in the present experiments, then the model would predict the lack of reinstatement found here. However, we were unable to find reinstatement even when the aversion had been only partially extinguished (Experiment 3), in which case it would be reasonable to suppose that the CS-US association was still partially intact following extinction. The present data are therefore inconsistent with the event-memory model.

The present results are also inconsistent with the context-conditioning account of reinstatement. On this view, if $\mathrm{LiCl}$ injections can be associated with contextual stimuli, and if contextual stimuli and tastes summate (cf. Krane, 1980; Willner, 1978), then it should be possible to reinstate an extinguished taste aversion with $\mathrm{LiCl}$ injections following extinction. Our results suggest that this may not be the case. It should be noted, however, that the context-conditioning account of reinstatement requires that the context be excitatory during testing if reinstatement is to be observed. Two considerations suggest the possibility that the present experiments might not have fulfilled this requirement. First, there is evidence to suggest that if exteroceptive (contextual) cues are to be associated with $\mathrm{LiCl}$, they must be novel when they are paired with LiCl (e.g., Archer \& Sjödén, 1981; Krane, 1980). In the traditional reinstatement design, the animal is exposed to the US in a familiar context; the test context was not novel when the rats were given reinstatement injections in the present experiments. Familiarity with the test context may have therefore prevented strong conditioning of the context. Second, although the visual and auditory stimuli were quite different in the rooms that provided the present test and conditioning contexts, the cages in which the rats were placed were identical in the two rooms. If the rats had failed to discriminate between the present test and conditioning contexts, then the illness-free exposure to the conditioning context (the home room) that they received following reinstatement injecting could have extinguished the associative strength of the test context (cf. Bouton \& Bolles, 1979). These considerations suggest that the context might not have been strongly excitatory during reinstatement testing. Experiment 2's finding that the reinstated rats' overall fluid consumption was depressed in the test context during reinstatement testing tends to weigh against this possibility. But similar results were not obtained in Experiments 1 and 3. It is thus conceivable that the present experiments did not provide conditions that the context-conditioning view would suggest are ideal for reinstatement.

Our results with the reinstatement procedure are similar to the results that have been obtained with related procedures that have been studied in taste aversion learning. Several investigators have ex- amined the effects of presenting the US independently of the taste CS following conditioning. As we found with the effect of exposure to the US following extinction, US exposure following conditioning does not usually change the strength of an established taste aversion (Brookshire \& Brackbill, 1976; Holman, 1976; Jacobs, Zellner, LoLordo, \& Riley, 1981; Riley, Jacobs, \& LoLordo, 1976; but see Colby \& Smith, 1977). Since exposure to the US following conditioning may be expected to modify the animal's memory of the US (cf. Rescorla, 1973, 1974), these results have also been interpreted as inconsistent with the event-memory model (see especially Jacobs et al., 1981). In a different set of experiments, Danguir and Nicolaidis (1977) found that rats would not reacquire an extinguished taste aversion when the taste was paired again with $\mathrm{LiCl}$ after extinction (but see Revusky \& Coombs, 1979). The present data bear some resemblance to these findings. The overall pattern of results seems to suggest that the strength of a taste aversion might be difficult to modify once it has been established or extinguished.

\section{REFERENCES}

ArChen, T., \& Suódén, P.-O. Environment-dependent tasteaversion extinction: A question of stimulus novelty at conditioning. Physiological Psychology, 1981, 9, 102-108.

Archer, T., Suödén, P.-O., Nilsson, L. G., \& Carter, N. Role of exteroceptive background context in taste-aversion conditioning and extinction. Animal Learning \& Behavior, 1979, 7, 17-22.

Archer, T., Suödén, P.O., Nilsson, L. G., \& Carter, N. Exteroceptive context in taste-aversion conditioning and extinction: Odour, cage, and bottle stimuli. Quarterly Journal of Experimental Psychology, 1980, 32, 197-214.

BAtson, J. D., \& Be8T, P. J. Drug-preexposure effects in flavoraversion learning: Associative interference by conditioned environmental stimuli. Journal of Experimental Psychology: Animal Behavior Processes, 1979, 5, 273-283.

BEST, M. R. Conditioned and latent inhibition in taste-aversion learning: Clarifying the role of learned safety. Journal of Experimental Psychology: Animal Behavior Processes, 1975, 1, 97-113.

Bouton, M. E. Role of conditioned contextual stimuli in two effects of retaining the unconditioned stimulus during extinction. Unpublished doctoral dissertation, University of Washington, 1980.

Bouton, M. E., \& Bolles, R. C. Role of conditioned contextual stimuli in reinstatement of extinguished fear. Journal of Experimental Psychology: Animal Behavior Processes, 1979, 5, 368-378.

Brookshire, K. H., \& Brackbill, R. M. Formation and retention of conditioned taste aversions and UCS habituation. Bulletin of the Psychonomic Society, 1976, 2, 125-128.

ColbY, J. J., \& SMITH, N. F. The effect of three procedures for eliminating a conditioned taste aversion in the rat. Learning and Motivation, 1977, 8, 404-413.

Danguir, J., \& Nicolaidis, S. Lack of reacquisition in learned taste aversions. Animal Learning \& Behavior, 1977, 5, 395-397.

Hoffman, H. S. The stimulus generalization of conditioned suppression. In D. I. Mostofsky (Ed.), Stimulus generalization. Stanford, Calif: Stanford University Press, 1965.

Holman, E. W. The effect of drug habituation before and after taste aversion learning in rats. Animal Learning \& Behavior, $1976,4,329-332$. 
Jacobs, W. J., Zellner, D. A., LoLohdo, V. M., \& Riley, A. L. The effect of post-conditioning exposure to morphine on the retention of a morphine-induced conditioned taste aversion. Pharmacology, Biochemistry and Behavior, 1981, 14, 779-785.

Krane, R. V. Toxiphobia conditioning with exteroceptive cues. Animal Learning \& Behavior, 1980, 8, 513-523.

Pavlov, I. P. Conditioned reflexes. London: Oxford University Press, 1927.

Quinsey, V. L., \& AYres, J. J. B. Shock-induced facilitation of a partially extinguished CER. Psychonomic Science, 1969, 14, 213-214.

Rescorla, R. A. Pavlovian conditioned inhibition. Psychological Bulletin, 1969, 72, 77-94.

Rescorla, R. A. Effect of US habituation following conditioning. Journal of Comparative and Physiological Psychology, $1973,82,137-143$.

Rescorla, R. A. Effect of inflation of the unconditioned stimulus value following conditioning. Journal of Comparative and Physiological Psychology, 1974, 86, 101-106.

Rescorla, R. A., \& Cunningham, C. L. The erasure of reinstated fear. Animal Learning \& Behavior, 1977, S, 386-394.
Rescorla, R. A., \& Cunningham, C. L. Recovery of the US representation over time during extinction. Learning and Motivation, 1978, 9, 373-391.

Rescorla, R. A., \& Heth, C. D. Reinstatement of fear to an extinguished conditioned stimulus. Journal of Experimental Psychology: Animal Behavior Processes, 1975, 1, 88-96.

Revusky, S., \& Coombes, S. Reacquisition of learned taste aversions. Animal Learning \& Behavior, 1979, 7, 377-382.

Riley, A. L., JAcobs, W. J., \& LoLondo, V. M. Drug exposure and the acquisition and retention of a conditioned taste aversion. Journal of Comparative and Physiological Psychology, 1976, 90, 799-807.

WiLlne R, J. A. Blocking of a taste aversion by prior pairings of exteroceptive stimuli with illness. Learning and Motivation, $1978,9,125-140$.

(Manuscript received June 16, 1981; revision accepted for publication November 16,1981 .) 